Editorial

\title{
To unite to be free
}

\author{
Carlos Renato Zacharias (PhD)
}

Editor-in-Chief, International Journal of High Dilution Research

Divide and Conquer! This is the most common way to solve the most complicated problems.

This motto has been proclaimed for long under the allegation that, when facing a serious problem, the best is to divide it into parts which, isolated, are easy to "conquer", in order to later reintegrate them under our strict surveillance. This motto might be applied everywhere, from the household budget to the conquest of a country.

It is undeniable that division has contributed to meet and overcome many challenges, and science is no different. Called reductionism, specialization, focus or excellence, it has help us advance in the knowledge of the universe, and made us able to devise a broad view on reality, to develop technology to solve several problems and, even to think who we are.

From nanotechnology to spatial navigation, from molecular biology to psychiatry, from the rights of individuals to social policy, our knowledge gives us power to understand, change and recreate reality.

However, ironically, we learned so much that we began to suspect that division does not lead us to conquer, but merely to the awareness that in many cases, reality cannot be divided into parts without losing some its essential characteristics.

I am not alluding to the holism of idealists, the spirit of the religious nor to the absolute of philosophers. I allude to mathematics of complex systems, to systemic biology, to the physics of many bodies, to sustainable global development. No doubt, the notion of complexity is a significant advance, although its influence is not felt everywhere. We are still in a phase of transition, of reductionist complexity. We have already risen our eyes to a wider view, but we are still afraid of what we see. Transition creates instability and fear, but we cannot advance without them!

To break boundaries it is, indeed, a conquest. However, it may be asked: how would it be to attain a state of transdisciplinarity, where the notion of "boundaries" itself is senseless? Inside and outside, beginning and end, body and mind, all integrated in one only concept! Without boundaries, we would be able to visualize new, and perhaps more important, aspects inherent to the phenomenon under observation. We would be perhaps also able to ponder, under a new light, on reality itself and who we are.

This may sound too abstract or utopian, so, let us have resource to an analogy, in order to imagine what is awaiting for us in the future. Mathematics, the most rigid and impersonal of sciences, offers to us a concrete example: Moebius' strip.

As a closed strip, it is senseless to attribute a beginning or an end to it, as there are no references. Even when it has two different sides, e.g. a clear and a dark one, Moebius' strip does not admit the definition of an internal and an external side. When the strip is cut along its length, instead of conquering order, we obtain one or more strips of similar properties, increasing, thus, the complexity of the system. When the strip is transversally cut, it loses its structure and is reduced to a simple rectangular strip.

Analogies may be didactic and even fun, but they do not always give the answers we are hoping for. Nevertheless, they may serve as stimuli for new challenges, for instance, the understanding of the effects of high dilutions.

When approaching this area, as we cross the mathematical boundaries imposed by the presence of matter, we lose the support offered by current scientific knowledge. Moreover, we are not even able to suggest which of the standard areas and fields of knowledge is the most suitable to host research in high dilutions. Here, we cannot merely divide the problem into smaller parts, as we do not know how to do it and we risk destroying its very nature.

To approach a phenomenon outside of a theoretical framework, through inconsistent experiments, will no lead us to its understanding. New conceptual grounds need to be established, and this requires a critical stance from researchers, cutting the ties to unfitting referents, without losing methodological coherence. Yet, it is imperative to release ourselves 
from vices acquired since the beginning of our training. Most probably, we will need to develop new methods, new experimental models, new notions, if we are to meet the challenge presented by high dilutions. We will have to thread a long path, without any signpost.
For this reason that Moebius' strip was chosen as the logo of IJHDR. It alludes to the long path opened to researchers in high dilutions. It alludes to the fact that to divide to conquer in fact can stop us in our path, by tying us to the past. The future requires a new motto: to unite to be free!

\section{(c)) EY-No-ND Licensed to GIRI}

How to cite this article: Zacharias CR. To unite to be free [Editorial]. Int J High Dilution Res [online]. 2008 [cited YYYY Mmm DD]; 7(23): 46-47. Available from: http://www.feg.unesp.br/ ojs/index.php/ijhdr/article/view/281/350. 